\title{
INSULTOS, PULLAS Y VITUPERIOS EN CELESTINA
}

\author{
Lourdes Albuixech \\ Southern Illinois University
}

Pero para mientes a la muger quanto la vieres yrada: cosas se dexa dezir por aquella boca ynfernal que non son de oyr nin escuchar. (Corbacho 155)

Alfonso Martínez de Toledo recordaba en la segunda parte de su Corbacho cómo las mujeres son maldicientes, sobre todo cuando son instigadas por la envidia o por la ira (cuarto y sexto pecados mortales, a los que son especialmente propensas). Suplía esta opinión con discursos animados en que las mujeres se desmedían en maldiciones, juramentos y denuestos, en cosas "que non son de oyr nin escuchar," como el célebre del huevo o el de la gallina perdidos. Son estampas que, allende retratar bastante desfavorablemente a la mujer, suponen una "trasfusión a la prosa del habla popular" (Castro Guisasola 173), que también encontramos en Celestina. Hablando de la influencia que el Arcipreste de Talavera operó en Celestina, Castro Guisasola se refería al "espíritu de observación y sano realismo, el arte exquisito de aprisionar con sorprendente gallardía en el estrecho marco de la prosa todo el tumulto callejero con su lenguaje elíptico y su modo de decir sentencioso y castizo, imitaciones numerosas de pormenor, y acaso acaso la afición a la prosa rimada" (Castro Guisasola 175-176). ${ }^{1}$ Ese "modo de decir castizo" incluye por igual sentencias y donaires, maldiciones e insultos, refranes y chistes, "motes y trufas del tiempo más viejo" (Celestina 344). En la carta "a un su amigo," Rojas se refiere a la mezcla de sentencias y donaires que tan bien le han parecido en el primer acto, y en los acrósticos, menciona los "dichos lascivos, rientes," el "oro de lata" o los "mill abrojos" con que ha dorado "el fin de aquesto que escrivo" (73).

La metáfora de la píldora dorada o endulzada dio la pauta a la lectura didáctica (Bataillon) o irónica (Gilman) de la obra, ${ }^{2}$ pero cuál era verdaderamente la intención de Rojas (y del primer autor) es algo que probablemente nunca llegará a dilucidarse del todo. Lo que es innegable, como ha destacado Dorothy Severin en varias ocasiones $(1979,1980,1987)$, es la negligencia de la crítica del 
siglo veinte en referencia al lado cómico de Celestina, tan evidente en cambio a los lectores contemporáneos a Rojas. Otros aspectos de la obra, como lo obsceno y el lenguaje soez, han sido igualmente desatendidos, víctimas de la pacatería crítica. En cuanto al primero de estos elementos, María Rosa Lida de Malkiel lamentaba que "los críticos apenas se han planteado el problema. Por lo común se han contentado con aplicarle de pasada alguna sanción moral, o lo han negado desde unas supuestas alturas estéticas" (325). El lenguaje vulgar, que incluye los insultos, juramentos, maldiciones, pullas, denuestos, vituperios, abominationes, execrationes, etc., permea enteramente el texto. Se trata, en palabras de Bakhtin, ${ }^{3}$ del "lenguaje del mercado," un tipo de lenguaje extraoficial, diferente del que se escuchaba en la Iglesia, en el palacio, en la corte o en otro tipo de instituciones (154). Me parece, por tanto, que no debemos ignorar su importancia y es mi propósito analizar aquí cuáles son sus funciones en la obra.

El uso de términos abusivos se advertía ya en la comedia latina, en la elegíaca y en la humanística, ${ }^{4}$ como han subrayado, entre otros, Saara Lilja, Lida de Malkiel y José Luis Canet Vallés. ${ }^{5}$ Sin embargo, es en Celestina donde se da la simbiosis más perfecta de estilo vulgar y estilo elevado. Es posible que ya desde el umbral de la Comedia, la carta al amigo, pueda apreciarse la influencia del lenguaje mercantil en Celestina. Para "vender" su remedio contra el amor mundano, mal endémico que aqueja incluso a su amigo y protector, Rojas elogia en términos exagerados (lo cual puede encubrir cierta socarronería) la medicina, los papeles mismos, fabricados no "en las grandes herrerías de Milán, mas en los claros ingenios de doctos varones castellanos" (69) y escritos en un estilo "jamás en nuestra lengua castellana visto ni oydo" (69). No sólo las alabanzas extremas, sino también el hecho mismo de ofrecer un remedio tan exaltado-una gran obra-para combatir una enfermedad o un afecto tan enojoso e inferior como el amor, recrean "that special marketplace atmosphere in which the exalted and the lowly [...] are leveled and are all drawn into the same dance" (Bakhtin 160). ${ }^{6}$ Se da en la carta la combinación tradicional de arte y medicina; se proclama la obra literaria como escritura que no sólo entretiene y es 'dulce,' sino que cura, lo que resulta tanto más irónico cuanto al final de la obra Pleberio recuerda el poder del amor, de cuya "congoxosa dança," que no hace melindres ni a la edad ni al estado de las personas, es casi imposible escapar.

Siguiendo el De remediis utriusque fortunae de Petrarca, Rojas afirma en el prólogo a la Tragicomedia que todo en el mundo-elementos, animales, peces, aves, hombre-vive en continua guerra. ${ }^{8}$ Esta natural contienda alcanza asimismo las opiniones de los lectores de la obra, "dando cada uno sentencia sobre ella a sabor de su voluntad" (80). Y es que, como advirtiera el "omne bueno" a su hijo en el exemplo II de El Conde Lucanor, "nunca farás cosa de que todos digan bien" (87). Toda la parte final del prólogo es original [de Rojas], y el eje central parece ser la palabra: unos loan, otros ríen, otros critican, otros añaden sumarios al principio de cada auto, otros litigan, otros piden que se 
alargue el proceso de los amores. El propio Rojas disiente de algunos de estos comentarios: "Unos les roen los huessos que no tienen virtud, que es la hystoria toda junta, no aprovechándose de las particularidades, haziéndola cuento de camino; otros pican los donayres y refranes comunes, loándolos con toda atención, dexando passar por alto lo que haze más al caso y utilidad suya" (80, énfasis mío). La palabra se convierte, así, en un instrumento más de porfía. Vale tanto para elogiar, como para ofender, y puede entenderse de infinitas maneras.

Entre los términos abusivos que más se repiten en Celestina encontramos 'torpe,'. 'maldito,' 'loco,' 'hydeputa' (o variantes como 'fi de puta'), 'necio,' 'traydor,' 'puto,' 'malvado,' 'simple,' 'vellaco,' 'bovo,' 'desvariado' y 'asno.' Algunos de éstos, como 'loco,' 'puto,' 'vellaco,' 'bovo' y 'asno,' cuando aparecen con un sufijo como -illo (loquillo, asnillo, vellaquillo, putillo, bovillo), -ito (loquito), -ico (simplezico, putico), -uelo (neciuelo), ilustran los "usos jocosos, suavemente ofensivos o simplemente cariñosos" del insulto (De Dios Luque, Pamies y Manjón 17). Este uso lúdico del insulto es puramente carnavalesco; su función no es ofender ni provocar a la risa, sino socializar. Estos términos resultan ambivalentes, ya que degradan y halagan simultáneamente, poniendo en entredicho las facultades mentales del interpelado y a la par estableciendo un vínculo entre éste y el interpelador. ${ }^{9}$

De todos los personajes, es sin duda la vieja alcahueta quien mejor ilustra este uso carnavalesco o festivo del insulto. Celestina conoce bien la función liberadora o terapéutica que puede tener el insulto. Sabe que mediante el uso de apelativos insultantes, puede aliviar o romper del todo la tensión que existe entre algunos personajes. Celestina trata de solventar sus diferencias con Pármeno salpicando su discurso de expresiones en que lo insultante se diluye entre diminutivos afectivos, como "neciuelo," "loquillo," "simplezico," "putico," "landrezilla" (118), "vellaquillo," "loquito" (120). Igualmente, echa mano del insulto cariñoso para ganarse a Lucrecia ("loquilla" [169]); a Sempronio ("loquillo," "bovo" [173], "loco" [175]); y de nuevo al pertinaz Pármeno ("loquillo" [193 y 198], "bovo" [199], "asno" [206]).

Además de esta función del insulto, en Celestina algunas acusaciones ofensivas y pullas se usan para hacer reír. Constituyen un elemento de distensión de la acción y forman parte del lado cómico o humorístico de la obra. Cuando Sempronio echa en cara a su amo "lo de tu abuela con el ximio" (96), es claro que la acusación no pasa de ser una inofensiva "porrada" para Calisto ("iMaldito sea este necio, y qué porradas dize!"), una simple broma (Green) o pulla (Armistead y Silverman), que más que escocer al amo, haría reír al oyente o lector en la época de Rojas. El problema es que en épocas modernas se ha distorsionado el significado de este tipo de chanzas, y se ha querido explicar la broma en términos más serios (Menéndez Pelayo, Forcadas, R.E. Barbera, Burke). ${ }^{10}$ 
Otro ejemplo del uso humorístico de lo abusivo se ve cuando Sempronio llega a casa de Celestina y Elicia lo recibe con las siguientes palabras: “ $¡ A y$, maldito seas, traydor! Postema y landre te mate ${ }^{11}$ y a manos de tus enemigos mueras y por crímenes dignos de cruel muerte en poder de rigurosa justicia te veas!" (105). Estos malos deseos constituyen una muestra de ironía premonitoria, puesto que efectivamente Sempronio acabará en manos de la justicia por el crimen perpetrado contra Celestina. Pero además manifiestan algún resabio de pullas, junto con otras maldiciones que Elicia añade inmediatamente después a éstas: “¡Nunca Dios te vea; nunca Dios te consuele ni visite!” (105), “ $\mathrm{Ha}$, don malvado! ¿Verla quieres? ¡Los ojos se te salten!” (106). Como demostrara Wickersham Crawford y prueban numerosos textos dramáticos del siglo XVI, era entonces popular en España el juego conocido como "echarse pullas," un tipo de tenzone o logomaquia emparentadas seguramente con los versus Fescennini, que se recitaban alternativamente y que consistian en "personal and often obscene taunts in which one person wished for another all sorts of misfortunes, and sometimes were employed in connection with wedding festivities" (153). Los participantes en este tipo de juegos, llegado el final, se separaban alegremente. Si bien es verdad que no se da en Celestina este intercambio alternativo de malos deseos, sí están presentes en esta situación en particular el trasfondo erótico, los insultos, las maldiciones y el humor. Sempronio mismo se ríe al escuchar las primeras maldiciones de su amante: “ $\mathrm{iHy}$, hy, hy! ¿Qué as, mi Elicia? ¿De qué te congoxas?" (105). Resulta claro que para Sempronio las maldiciones de Elicia forman parte del juego amoroso. Su risa revela su gozo al verse reconvenido por su amante y da una pauta sobre la manera en que ha de interpretarse el pasaje. El lector u oyente, además, se divierte por partida doble, pues contempla la ironía tras el aparente enojo de la prostituta.

Saara Lilja señaló que en la comedia latina "slaves are the principal figures in comic scenes of abuse. Incessantly abused by their masters, they find a satisfactory compensation in abusing each other whenever the opportunity arises, and, moreover, those free people who are low enough in the social scale-such as procurers-and sometimes even the master, behind his back" (52). En Celestina son los criados y la alcahueta los que más echan mano del lenguaje abusivo. Como en la comedia romana, la risa arranca en ocasiones de instancias en que los criados se insultan, abusan de otros personajes socialmente inferiores y critican a su amo a sus espaldas. En la escena con que se abre el acto VI encontramos estos tres aspectos juntos: Sempronio maldice e insulta a Pármeno [ $; \mathrm{O} \mathrm{mal}$ fuego te abrase, que tú hablas en daño de todos y yo a ninguno offendo! $¡ \mathrm{O}$ intollerable pestilencia y mortal te consuma, rixoso, imbidioso, maldito! [...] ¡Vete de aquí a la mala ventura!" (178)] porque Pármeno ha insultado a la proxeneta apodándola "puta vieja" (178). El joven criado no escarmienta, y se mete ahora con el amo, en comentarios aparte, llamándolo "este loco," "desvariado" y "el perdido" (180), ganándose más vituperios por parte de su compañero, que lo califica de "maldiziente venenoso" (180). 
Aparte de los insultos cariñosos o socializadores y los insultos humorísticos, un número considerable de términos y expresiones se usan en Celestina con el afán de ofender o vejar. En cierto modo, estos insultos actúan como niveladores ya que aparecen en boca de distintos personajes, desde los criados y Celestina hasta Calisto y Melibea. Pero mientras que los personajes de clase social más elevada pueden referirse a sus subordinados en términos vejatorios, los criados y las prostitutas sólo pueden hablar en estos términos entre sí. A ello alude Areúsa en el acto IX cuando Lucrecia llega a interrumpir el banquete:

Assí goçe de mí, que es verdad, que éstas que sirven a señoras [...] Nunca tratan con parientas, con yguales a quien pueden hablar tú por tú $[\ldots]$. ¡O tía, y qué duro nombre y qué grave y sobervio es «señora» contino en la boca. Por esto me bivo sobre mí, desde que me sé conoscer, que jamás me precié de llamar de otrie sino mía. Mayormente destas señoras que agora se usan. (232)

Con estas señoras, continúa diciendo Areúsa, se gasta lo mejor del tiempo y sólo pagan con insultos como "ladrona," "puta," "tiñosa," "vellaca," "golosa," "puerca," "çuzia," "necia," "desaliñada," "mala mujer," "Y tras esto mil chapinazos y pellizcos, palos y açotes" (233). Por eso, cuando quieren insultar a sus amos, los criados lo hacen en apartes cínicos y mordaces o en ausencia del insultado ante una tercera persona.

Calisto pasa con especial soltura de los elogios a los abusos, en el tratamiento que propina a sus criados. En la primera escena con Sempronio, Calisto insulta a su sirviente llamándolo "este maldicto" (87) y "malvado" (88), lo impreca con pullas como “ ¡Ansí los diablos te ganen!, ansí por infortunio arrebatado perezcas, o perpetuo intolerable tormento consigas, el qual en grado incomparablemente a la penosa y desastrada muerte que spero traspassa" (87-88), y termina mandándolo "con el diablo" (89). La violencia verbal del amo no parece ofender al criado hasta que, de manera insolente, Sempronio replica al " ¡Ve con el diablo!" de Calisto diciendo: "No creo según pienso, yr conmigo el que contigo queda" (89). ${ }^{12}$ Este exabrupto tiene una función fisiológica, "for after childhood, relief in tears and wailing is rightly discouraged, and groans are also considered a signal of extreme weakness. Silence after suffering is usually impossible. The nervous system demands some expression that does not affect towards cowardness and feebleness, and, as a nervous stimulant in a crisis, swearing is unequalled" (Graves 32).

El maltrato verbal del amo parece tener un efecto acumulativo en el sistema nervioso de Sempronio quien, sin poder tolerar más el abuso, paga-aunque sea a través de un aparte-a Calisto con la misma moneda. $Y$ a partir de ahora, el criado que había sobrellevado con tanta calma las asperezas proferidas por Calisto, 
se atreve a tildarlo de "loco," "herege" (92), "pusillánime," "fi de puta" (95), "necio" y "asno" (101) en sendos apartes. Estos insultos de Sempronio (a diferencia de la salida de tono que acabamos de ver) no son propiamente reacciones a insultos de Calisto, sino más bien a comentarios de éste que le sorprenden o que ofenden por contradecir la religión cristiana o las expectativaś de comportamiento masculino (fuera, claro está, del comportamiento masculino literario, como aquel prescrito por la narrativa sentimental, que es por el que se rige Calisto). Los insultos murmurados por el criado socavan el discurso amoroso-sentimental de Calisto, contribuyendo así a la parodia del enamorado.

Al igual que su compañero Sempronio, Pármeno sufre los vituperios de Calisto (enojoso, loco, necio [134], vellaco, mal criado [135], terrón de lisonja, bote de malicias, el mismo mesón y aposentamiento de la embidia, perdido [136]) con mayor o menor serenidad, pero no tardamos en darnos cuenta de que se siente ofendido. Una vez solo, el criado lamenta el mal 'verbal' que recibe de su amo en pago a su fidelidad: " $\mathrm{O} O$ desdichado de mí!; por ser leal padezco mal. Otros se ganan por malos, yo me pierdo por bueno. El mundo es tal; quiero yrme al hilo de la gente, pues a los traydores llaman discretos, a los fieles necios. Si [yo] creyera a Celestina con sus seys dozenas de años acuestas, no me maltratara Calisto" (137).

Cuando, poco después, llega Sempronio con Celestina a las puertas de Calisto, éste manda a Pármeno a ver quién es, no sin antes llamarle "maldito sordo" (108). El criado anuncia que "Sempronio y una puta vieja alcoholada davan aquellas porradas" (108). Calisto se impacienta e increpa " $;$ Calla, calla, malvado, que es mi tía; corre, corre, abre!” (108), pero Pármeno, que conoce bien a Celestina, aclara a su amo " ¿Y tú piensas que es vituperio en las orejas désta el nombre que la llamé? No lo creas, que ansí se glorifica en lo oyr, como tú quando dizen: «Diestro cavallero es Calisto»" (108). Saara Lilja ha señalado que "a pejorative adjective is not a term of abuse, if it simply makes known a disagreeable trait of character" (11), y es evidente que para el joven criado no puede haber ofensa en esta descripción incontrovertible de la alcahueta. Pero por más que Pármeno se empeñe en que Celestina es "por tal título conoscida" (108) y enumere los distintos ruidos que "el tal nombre representan" (109), vemos que la vieja se ofende bastante al son de tal apelativo. Cuando Pármeno se refiere a ella como "flaca puta vieja" (120), la tercera reacciona algo molesta: “¡Putos días vivas, vellaquillo! ¿Y cómo te atreves?” y, más adelante le recuerda "que tan puta vieja era tu madre como yo!" (120). Como recuerda Miguel Casas Gómez, "la palabra "puta" y sus expresiones malsonantes constituyen uno de los tacos o insultos más asiduos de nuestra vida cotidiana" (95), y ya era así en la época de Rojas, como ha demostrado José Luis Alonso Hernández en su inventario del lenguaje germanesco de los siglos XVI y XVII. ${ }^{13}$

Nos damos cuenta, además, de que a la vieja le ofende oírse llamar ciertas 
cosas por lo que ocurre de camino a casa de Pleberio. En plena calle, Celestina se amedrenta ante la posibilidad de ser descubierta por la justicia. Antes de reparar en los agüeros favorables, lo que empuja a la alcahueta a seguir es "el qué dirán" Sempronio y, sobre todo, Calisto. Casi resulta irónico que pese más para la vieja locuaz la violencia de la palabra que la que le espera de ser atrapada por la justicia (muerte, manteamiento, azotes, encorozamiento). Celestina imagina los "denuestos raviosos" (150) que le echará en cara y a voces el enamorado; la llamará "puta vieja," "alcahueta falsa" y "vieja traydora" (150). Lo peor es que estas imaginadas voces de oprobio se literalizan momentos después, cuando Melibea descubre los motivos reales de Celestina, y en un arranque de cólera la nombra "alcahueta falsa, hechizera, enemiga de honestidad, causadora de secretos yerros" (161), "malvada," "vieja maldita" y "traydora" (162). Posteriormente, la vieja recordará a Calisto los "inominiosos nombres con cuyos títulos asombran a los niños de cuna" con que la magulló la joven (182) ${ }^{14}$ Celestina, insultada a su cara y a sus espaldas, todavía tiene que escuchar injurias de boca de los dos criados antes de morir traspasada por la espada de Sempronio: "o vieja avarienta, garganta muerta de sed por dinero" y "doña hechizera" (274).

Pocos personajes de la obra se salvan de ser denigrados a sus espaldas, ante un tercero. Melibea describe a Calisto ante Celestina y Lucrecia como: "loco saltaparedes, fantasma de noche, luengo como cigüeña, figura de paramiento malpintado" (162); la "gentil" Melibea en realidad da asco, según Areúsa y Elicia. Ésta, en el acto XV, llega incluso a referirse a ella como "la loca de Melibea" (296) y el "estiércol" de Calisto (299). Pármeno y Sempronio denominan muchas veces "puta vieja" a Celestina cuando hablan de ella. Escondida tras un paramento en casa de Areúsa, Elicia se refiere a Sosia como "hydeputa el pelón" (309), "don handrajoso" y "el asno" (312), y la propia Areúsa lo llama "vellaco" (312) en cuanto sale de la casa. A Centurio, Areúsa lo describe como "aquellotro cara de ahorcado" (313) y como "el vellaco" (313); el soldado fanfarrón alude a sus dos visitantes como "estas putas" (317) y Tristán recuerda a Sosia que Areúsa es "marcada ramera," "malvada hembra" y "arrufianada mujer" (319). La maledicencia se convierte, por tanto, en uno de los vicios más ponzoñosos de la sociedad celestinesca pero es asimismo reveladora de información respecto a los ofensores (De Dios Luque, Pamies y Manjón 24).

La descripción que hace Melibea de la fisonomía del joven caballero que la pretende revela la importancia que tiene para la joven la imagen. Este rasgo de la personalidad de Melibea parece corroborarse en la descripción que de ella hacen a su vez las dos prostitutas. Elicia explica que "Aquella hermosura por una moneda se compra en la tienda," y que "si algo tiene de hermosura es por buenos atavíos que trae" (226); Areúsa añade que "Por una vez que haya de salir donde pueda ser vista, enviste su cara con hiel y miel, con unas tostadas y higos passados, y con otras cosas que por reverencia de la mesa dexo de dezir" (226). Pero a su vez, estas descripciones más que informar sobre Melibea, informan 
sobre las prostitutas y su propensión a la envidia. El apelativo de "puta vieja" con que se refieren a Celestina los criados revela que desconfían de ella y, acaso, que la temen. ${ }^{15}$ Los insultos de ambas prostitutas a Sosia y a Centurio ilustran el desprecio que sienten hacia estos personajes, y lo mismo puede decirse de los denuestos que a sus espaldas reciben las dos mujeres de boca del soldado fanfarrón y de Tristán.

Pese a la desatención que ha recibido hasta hoy este aspecto de Celestina, es innegable la importancia que ocupa este lenguaje mercantil en la obra. Como dicen De Dios Luque, Pamies y Manjón, "esta faceta oscura del léxico [...] florecía bastante en la literatura, desde los Juegos de escarnio y las Cantigas d'escarnho y maldizer hasta los poemas satíricos de Quevedo [...]" (21). ${ }^{16}$ Es posible que hoy resulte chocante encontrar este lenguaje en una obra maestra de la literatura española, pero no lo era en la época ni el lugar en que se escribió. En Salamanca, el ambiente juvenil y festivo propiciaba ceremonias como el vejamen, "a derogatory speech about the [doctoral] candidate which, on occasion, descended to gross insults hugely enjoyed" (Gilman, The Spain 296). Rojas, un maestro en la absorción de fuentes literarias diversas, fue igualmente un genio en la absorción del habla popular, que despliega sin tapujos en las memorables páginas de su obra. Después de él, las continuaciones de Celestina pierden bastante en agilidad y realismo verbal popular, en parte por el recorte que sus autores llevaron a cabo de insultos, pullas y vituperios. ${ }^{17}$

$* * *$

\section{NOTAS}

${ }^{1}$ Stephen Gilman (The Spain 325) cree que hubo de existir una edición impresa del Corbacho en 1495, que sería la que habría manejado Rojas. Para el valor del discurso callejero en El Arcipreste de Talavera, puede consultarse Menéndez Pelayo, Orígenes CIV-CXIV.

${ }^{2}$ El didactismo de la obra fue defendido por Marcel Bataillon en «La Célestine» selon Fernando de Rojas. Stephen Gilman estaba convencido de que la intención final había que buscarla en el planto de Pleberio y de que las afirmaciones tocantes a la moral que leemos en los acrósticos, en la carta al amigo o en el síguese, eran puramente convencionales (The Spain 357-367). Dorothy Severin, tras resaltar la contradicción que existe entre la intención de la Comedia y de la Tragicomedia-esta última más moralista-concluye diciendo que, al menos originalmente, su motivación era "de orden artístico y estético fundamentalmente, y que lo que pretendía era escribir un relato que deleitase, y al mismo tiempo desencantase, a los sufridos amadores" $(1987,25)$, aunque parece haberse asustado entre la primera y la segunda edición de Celestina y de ahí que añadiera tantas indicaciones sobre la recta finalidad de la obra en la Tragicomedia.

${ }^{3}$ Algún resabio de esto queda en la expresión "habla como una verdulera," 
que todavía se escucha hoy en día.

4 Para las relaciones entre la comedia romana y Celestina, véanse Castro Guisasola y Grismer. Lida de Malkiel analizó minuciosamente el influjo que operaron la comedia latina, la elegíaca y la humanística en la obra de Fernando de Rojas.

${ }^{5}$ Saara Lilja estudió en particular los términos abusivos en la comedia romana de Plauto y Terencio. En relación a la comedia elegíaca, Lida de Malkiel se refiere, por ejemplo, a las "bromas soeces al amo" (36). Canet Vallés, por su parte, menciona el "lenguaje tipificado y medio burlesco, en el que se basa gran parte de la comicidad" (26) rastreable en la comedia humanística y en obras como el Corbacho.

${ }^{6}$ Cabe notar que esta lectura de la carta preliminar estaría en consonancia con la teoría de Severin en relación a la mayor laxitud de la Comedia frente a la Tragicomedia.

7 Para la relación entre literatura y medicina, véase Michael R. Solomon, The Literature of Misogyny in Medieval Spain: The "Arcipreste de Talavera" and "The Spill."

${ }^{8}$ Como apuntó Gilman en The Spain of Fernando de Rojas, "Awareness of life as warfare, warfare ranging from major clashes of nations and cultures through the minor skirmishes and aggressions which make up the texture of human existence, to the historyless ferocity of the animal world, was, thus, at once a theme of $L a$ Celestina and a fundamental part of the experience of being a converso" (186).

9 Pancracio Celdrán dice que la voz 'torpe,' del latín turpis, es muy antigua y se encuentra ya en el Cantar de Mío Cid; también 'maldito' es voz de uso muy antiguo, documentada ya en el Libro de Alexandre; igualmente, 'loco' aparece en castellano desde el origen del idioma (usan ya la palabra Berceo y Sem Tob de Carrión); el término 'hideputa,' que había sido insulto grave, en el siglo XV se convirtió en "exclamación ponderativa sin intención de injuria" (141); 'necio' también es de uso antiguo; 'puto' era un insulto grave y frecuente en el siglo XV; 'simple' aparece ya en Berceo; 'vellaco' (o 'bellaco'), término que suele acompañar como refuerzo mutuo a 'hideputa,' aparece ya en el Libro de buen amor y era insulto grave "cuando se dirigía a persona de condición y respeto, y no entre rufianes o criados" (22); 'bobo' comenzó a emplearse en castellano "hacia finales del siglo XV" (27); el uso de la voz 'asno' está documentado, según Celdrán, ya hacia el año 1000.

${ }^{10} \mathrm{Otis} \mathrm{H}$. Green pensaba que el comentario de Sempronio formaba parte de una tradición medieval y renacentista que asociaba al simio con la pasión carnal, y que por lo tanto no hay que entenderlo más que como una broma. Samuel Armistead y Joseph Silverman confirmaron que esta tradición del mono amante de mujeres era conocida en España, aportando ejemplos literarios españoles en que se echa mano del tema Antonio de Torquemada y Lope de Vega. Para estos críticos, con esta alusión a bestialidad, Sempronio le "echa una pulla" a Calisto (17, nota 7$)$. Alberto Forcadas piensa, siguiendo a Menéndez Pelayo, que en la acusación hay una "difamación de la limpia sangre" de Calisto, y que, más específicamente, la palabra 'ximio' alude a 'judío.' Por último, James Burke sugiere que el pasaje encubre la influencia de dos tradiciones, "that of the lover affected by the object of his desire and the power of a woman's imagination to impress an image of this object upon the fetus" (88).

${ }^{11}$ Este tipo de maldición ("mala landre te coma o te mate") era de uso frecuente 
en el siglo $\mathrm{XV}$, y aparecen varias instancias en que se utiliza esta expresión u otra similar en Celestina: “¡Mala landre te mate; y cómo lo dice el desvergüençado!” (120), "O intollerable pestilencia y mortal te consuma, rixoso, imbidioso, maldito!" (178), “ ¡De mala cançre sea comida esa boca desgraciada, enojoso!” (229), "Landre me mate si no me espanto en verte tan fiero" (269). Otra maldición frecuente en la obra es la relacionada con el fuego: " $P$ Pues fuego malo te queme, que tan puta vieja era tu madre como yo!" (120), dice Celestina a Pármeno; “Quemada seas, alcahueta falsa" (161), desea Melibea a Celestina; “ $\mathrm{O}$ mal fuego te abrase, que tú hablas en daño de todos y yo a ninguno offendo!” (178), dice Sempronio a Pármeno. Sin duda, la muestra más larga de maldiciones en sarta, aunque sin que estén presentes las personas a quienes se desean estos males, es la de Elicia en el acto XV, que implora para Calisto y Melibea "mal fin ayan vuestros amores, en mal sabor se conviertan vuestros dulçes plazeres; tórnese lloro vuestra gloria, trabajo vuestro descanso; las yervas delytosas donde tomáys los hurtados solazes se conviertan en culebras; los cantares se os tornen lloro; los somebrosos árboles del huerto se sequen con vuestra vista; sus flores olorosas se tornen de negra color" (298).

${ }^{12}$ Esta despedida contrasta con la que, unas páginas después, intercambian amo y criado, una vez que Sempronio promete traer a Celestina: "Ya voy; quede Dios contigo," a lo que Calisto responde:"Y contigo vaya" (104). Como vemos, el tono se ha dulcificado bastante.

${ }^{13}$ Alonso Hernández menciona ejemplos en Celestina en que se usan otras voces (errada, enamorada, pájara, prima, devota) en lugar de 'puta' para referirse al mismo oficio $(26,33,50,54)$. Según Pancracio Celdrán, este improperio se usaba ya desde época antigua y "se encuentra entre las cinco palabras mayores, así llamadas antaño las más injuriosas, ofensivas e insultantes, siendo las otras: sodomita, renegado, ladrón y cornudo" (274).

${ }^{14}$ Celestina reproduce bastante libremente los insultos de Melibea: omite algunos y añade otros como "barvuda" y "malhechora," que Melibea nunca pronunció. La vieja exagera socarrónamente el habla y los visajes de Melibea, parodiando de este modo el topos de los síntomas de amor (Severin 1987, 182,

n. 10).

${ }^{15}$ Según Charles Flynn, "The fear of supernatural powers serves in many cultures to protect older members of the tribe or village. Old persons are often viewed as the most likely holders of supernatural power; hence, younger members' fear of their supernatural abilities allows old people a certain defense against insult and ridicule which they would not otherwise be able to possess because of their relative inability to respond to insult in an overt, violent manner" (73). Quizás esto explique el por qué los criados siempre hablan mal de Celestina a sus espaldas.

${ }^{16}$ Véase, además, el artículo de Maurizi sobre las pullas en el teatro castellano de finales del siglo XV y principios del XVI, y el de Joly sobre la diversión de echar pullas. Según Covarrubias, ciertos espacios y momentos, como la vendimia o los encuentros entre caminantes, se prestan al intercambio de pullas. Joly añade que otros lugares de encuentro provisional entre personas, como las ventas, podían propulsar también el uso de pullas. La casa de Celestina, una casa de citas provisorias para el intercambio o comercio de placer, un universo al unísono dentro y al margen de la sociedad, constituye, como hemos visto, otro espacio idóneo para el uso de 
lenguaje soez, chistes obscenos y maldiciones.

${ }^{17} \mathrm{La}$ literatura celestinesca que incluye Canet Vallés en su compendio de teatro representable reduce considerablemente el uso de insultos. La Égloga de la tragicomedia de Calisto y Melibea, compuesta por Pedro Manuel de Urrea, siendo prácticamente una réplica en verso de Celestina, es la más abundante en insultos. El resto de las obras (Penitencia de amor, del mismo Urrea, y las anónimas Comedia Thebayda, Comedia Hipólita y Comedia Serafina) son ricas en eufemismos sexuales y no carecen de lenguaje soez, pero en menor medida que Celestina.

\section{OBRAS CITADAS}

Alonso Hernández, José Luis. El lenguaje de los maleantes españoles de los siglos XVI y XVII: La Germania (Introducción al léxico del marginalismo). Salamanca: Universidad, 1979.

Armistead, Samuel G. y Joseph H. Silverman. "Algo más sobre «Lo de tu abuela con el ximio» (La Celestina, I): Antonio de Torquemada y Lope de Vega." Papeles de Son Armadans 69 (1973): 11-18.

Bakhtin, Mikhail. Rabelais and His World. Trad. H. Iswolsky. Bloomington: Indiana UP, 1984.

Barbera, R.E. "Medieval Iconography in the Celestina." Romanic Review 61 (1970): 5-13.

Bataillon, Marcel. 'La Célestine' selon Fernando de Rojas. París: Didier, 1961.

Burke, James F. "Calisto's Imagination and His Grandmother's Ape." La Corónica 5 (1977): 84-90.

Canet Vallés, José Luis. De la comedia humanistica al teatro representable (Égloga de la tragicomedia de Calisto y Melibea, Penitencia de amor, Comedia Thebayda, Comedia Hipólita, Comedia Serafina). València: Universitat, 1993.

Casas Gómez, Miguel. La interdicción lingüistica. Cádiz: Universidad, 1986.

Castro Guisasola, F. Observaciones sobre las fuentes literarias de 'La Celestina.' Madrid: Jiménez y Molina, 1924. Reimp. Madrid: CSIC., 1973.

Celdrán, Pancracio. Inventario general de insultos. Madrid: Ediciones del Prado, 1995.

Covarrubias Horozco, Sebastián de. Tesoro de la lengua castellana o española. Ed. Felipe C.R. Maldonado. Madrid: Castalia, 1994.

De Dios Luque, Juan de, Antonio Pamies y Francisco José Manjón. El arte del insulto: Estudio Lexicográfico. Barcelona: Península, 1997.

Flynn, Charles P. Insult and Society. Patterns of Comparative Interaction. Port Washington, N.Y./ London: Kennikat Press, 1977.

Forcadas, Alberto M. "Otra solución a «Lo de tu abuela con el ximio» (Aucto 1) de La Celestina." Romance Notes 15 (1974): 567-571.

Gilman, Stephen. The Art of 'La Celestina.' Madison, WI: U Wisconsin P, 1956.

. The Spain of Fernando de Rojas. The Intellectual and Social Landscape of 
'La Celestina.' Princeton: Princeton UP, 1972.

Graves, Robert. Lars Porsena or The Future of Swearing and Improper Language. London: Kegan Paul, Trench, Trubner; New York: E.P. Dutton \& Co., 1928. Green, Otis H. "Lo de tu abuela con el ximio (Celestina, Auto 1)." Hispanic Review 24 (1956): 1-12.

Grismer, Raymond Leonard. The Influence of Plautus in Spain Before Lope de Vega. New York: Hispanic Institute, 1944.

Joly, Monique. "Sémantique et littérature: Nouvelles remarques sur un certain type de plaisanterie (echar pullas)." En, Actes du XIIIe congrès international de linguistique et philologie romanes tenu à l'Université Laval, I. Eds. M.Boudreault y F.Mohren. Quebec: Press de l'Université de Laval, 1979. 843-857.

Lida de Malkiel, María Rosa. La originalidad artística de 'La Celestina.' Buenos Aires: EUDEBA, 1970 ( $2 \mathrm{a}$ ed.).

Lilja, Saara. . Terms of Abuse in Roman Comedy. Helsinki: Suomalainen Tiedeakatemia, 1965.

Manuel, Don Juan. El Conde Lucanor. Ed. A. I. Sotelo. Madrid: Cátedra, 1991. Martínez de Toledo, Alfonso. Arcipreste de Talavera o Corbacho. Ed. J. González Muela. Madrid: Castalia, 1985.

Maurizi, Françoise. "Les «Pullas» dans le théâtre castillan de la fin du Xvedébut du XVIe." En Fragments et formes brèves. Ed. B. Pelegrín. Aix-enProvence: U Provence, 1990. 5-17.

Menéndez Pelayo, Marcelino. Orígenes de la novela, I. Madrid: Bailly Bailliere, $1925^{2}$.

Rojas, Fernando de. La Celestina. Ed. D. S. Severin. Madrid: Cátedra, 1987.

Severin, Dorothy S. "Humour in La Celestina." Romance Philology 32 (1979): 274-291.

.Parodia y sátira en La Celestina." En Actas del Sexto Congreso Internacional de Hispanistas. Eds. A. M. Gordon y E. Rugg. Toronto: Dept. of Spanish and Portuguese U Toronto, 1980. 695-697. 1987. 11-64.

Solomon, Michael R. The Literature of Misogyny in Medieval Spain: The 'Arcipreste de Talavera' and 'The Spill.' Oxford/New York: Cambridge UP, 1997.

Wickersham Crawford, J.P. "Echarse pullas: A Popular Form of Tenzone." Romanic Review 6 (1915): 150-164.

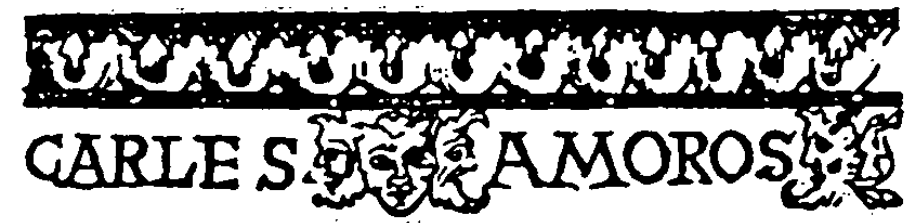

Marco (detalle) Barcelona, 1529) 